\title{
Transparency anticorrosion coatings prepared from alumina-covered graphene oxide/polyimide nanocomposites
}

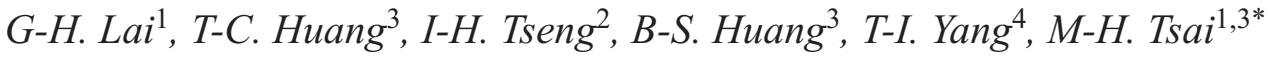 \\ ${ }^{1} \mathrm{Ph}$. D. Program, Graduate Institute of Precision Manufacturing, National Chin-Yi University of Technology, \\ 41170 Taichung, Taiwan \\ ${ }^{2}$ Department of Chemical Engineering, Feng Chia University, 40724 Taichung, Taiwan \\ ${ }^{3}$ Department of Chemical and Materials Engineering, National Chin-Yi University of Technology, 41170 Taichung, \\ Taiwan \\ ${ }^{4}$ Department of Chemical Engineering, Chung Yuan Christian University, 32023 Chung Li, Taiwan
}

Received 19 January 2019; accepted in revised form 3 April 2019

\begin{abstract}
In this study, a novel alumina-covered graphene oxide/polyimide (AlGO/PI) nanocomposite was developed as an anticorrosion coating material. The hydroxyl groups on GO reacted with aluminum isopropoxide via a sol-gel process to yield AlGO nanosheets. The characterization and structure were confirmed by Fourier transform infrared spectrometry, X-ray photoelectron spectroscopy, field emission scanning electron microscopy, and field emission transmission electron microscopy. Subsequently, GO and AlGO were incorporated into a PI matrix, leading to the formation of GO/PI and AlGO/PI nanocomposites. Well-dispersed AlGO nanosheets in the PI matrix acted as effective additives to enhance the water barrier properties of $\mathrm{GO} / \mathrm{PI}\left(58 \mathrm{~g} /\left(\mathrm{m}^{2} \cdot\right.\right.$ day $\left.)\right)$ and AlGO/PI $\left(43 \mathrm{~g} /\left(\mathrm{m}^{2} \cdot\right.\right.$ day $\left.)\right)$ coatings. Most importantly, the resultant AlGO/PI films exhibited excellent optical transparency $(>75 \%)$ and anticorrosion properties. Electrochemical measurements of corrosion potential, polarization resistance, and corrosion current as well as electrochemical impedance spectroscopy confirmed that the AlGO/PI nanocomposites exhibited better anticorrosion properties than GO/PI nanocomposites. This is likely because the insulating layer of alumina on GO can isolate the charge transfer pathway between GO and the metal substrates, leading to improved anticorrosion behavior.
\end{abstract}

Keywords: polymer composites, polyimide, alumina-covered graphene oxide, anticorrosion

\section{Introduction}

Polymer/filler nanocomposites have received significant attention because of their excellent electrical, mechanical, thermal, barrier, and anticorrosion properties [1]. Nanofillers such as clay [2,3], silica [4, 5], metallic oxide [6, 7], boron nitride [8,9], $\mathrm{ZrP}[10,11]$, CNT [12] and alumina [13] have been conventionally incorporated within a polymer matrix or coated on the surface of the polymer film to improve their barrier and anticorrosion properties [14-16].

Recently, graphene, graphene oxide (GO), and reduced graphene oxide (rGO) have been demonstrated to have a strong anticorrosion ability because of their layered structure. Chen et al. [17] demonstrated that graphene films grown by chemical vapor deposition (CVD) can effectively protect metal surfaces from corrosion. Compton et al. [18] found that a polystyrene (PS) film with low graphene loading was more effective in reducing the $\mathrm{O}_{2}$ permeability of PS than the clay/polymer composite. Chang et al. [14] showed the application of polyaniline/graphene (PANI/ graphene) composites as anticorrosion coatings for steel. The PANI/graphene coatings effectively protected the steel from corrosion because of their good gas barrier properties. Well-dispersed graphene in a polymer matrix, with a relatively high aspect

$\overline{{ }^{*} \text { Corresponding author, e-mail: tsaimh@ncut.edu.tw }}$ (c) BME-PT 
ratio compared to clay, exhibits enhanced gas barrier properties. Hence, graphene/PANI composites are more effective than clay/PANI composites in anticorrosion applications. However, Schriver et al. [19] recently found that CVD-grown graphene can prevent $\mathrm{Cu}$ and $\mathrm{Si}$ from oxidizing and corroding only for short periods (few minutes to hours). This is because oxygen and moisture infiltrate defects in the graphene structure and oxidize the surface of the underlying substrate over a long period of time $(>17 \mathrm{~h})$. In addition, using graphene coatings can promote corrosion by facilitating electrochemical reactions. Electron transfer between the graphene and substrate accelerate the corrosion of the $\mathrm{Cu}$ substrate. Therefore, Sun et al. [20] used low-electrical-conductivity graphene/pernigraniline/polyvinylbutyral (PVB) composites to solve this problem. PVB can cut off the electron pathways between metals and graphene, subsequently reducing the efficiency of electron transfer. Potentiodynamic polarization and electrochemical impedance spectroscopy tests demonstrated that the developed coating is an outstanding barrier against corrosive media. Yang et al. [21] used liquid-phase exfoliation fluorographene nanosheets/epoxy composites to increase the surface roughness. This method not only provides a superhydrophobic coating but also protects the matrix from corrosion. Zhan et al. [22] utilized the bio-inspired modification of a graphene oxide $/ \mathrm{Fe}_{3} \mathrm{O}_{4}$ hybrid. They found that the hybrid could effectively disperse in an epoxy matrix and, thus, enhance the interfacial adhesion, showing excellent anticorrosion properties.

The polymer matrix used in this study is an aromatic polyimide (PI) that shows unique optical properties, good chemical stability, and outstanding thermal and mechanical properties $[23,24]$ as opposed to conventional polymers. Because of these noteworthy properties, PI films have significant potential for advanced applications in the electronic industry [25] as aerospace materials [26], gas separation membranes [27], and anticorrosion materials [28, 29]. Graphene-related nanofillers are also promising gas barrier materials for polymer matrices. Improved barrier properties of PI were achieved by blending with $\mathrm{GO}$, but the anticorrosion properties were effective for only a short time $(<1 \mathrm{~h})$.

In this study, we designed alumina-covered graphene oxide (AlGO) nanosheets and incorporated them into PI for use as a coating material. The prepared AlGO/PI composite showed superior long-term an- ticorrosion properties as compared to pristine PI and GO/PI composites. These promising results can be attributed to the insulated layer of alumina hydroxide on $\mathrm{GO}$ that reduces the charge transfer between GO and the metal substrates and improves the anticorrosion properties of the material.

\section{Materials and methods}

\subsection{Materials}

( $N, N$-Dimethylacetamide (DMAc, TEDIA, America), potassium permanganate $\left(\mathrm{KMnO}_{4}, \mathrm{TCI}\right.$, Japan), sulfuric acid $\left(\mathrm{H}_{2} \mathrm{SO}_{4}\right.$, SHOWA, Japan), hydrochloric acid ( $\mathrm{HCl}$, SHOWA, Japan), phosphoric acid $\left(\mathrm{H}_{3} \mathrm{PO}_{4}\right.$, SHOWA, Japan), hydrogen peroxide $\left(\mathrm{H}_{2} \mathrm{O}_{2}\right.$, SHOWA, Japan), alcohol $\left(\mathrm{C}_{2} \mathrm{H}_{5} \mathrm{OH}\right.$, ECHO, Taiwan), aluminum isopropoxide (AlIP, TCI, Japan), graphite (Alfa-Aesar, America), 4-4'-diaminodiphenylether (ODA, Sigma-Aldrich, America), and 4,4'-(4,4'-isopropylidenediphenoxy)bis(phthalic anhydride) (IDPA, Sigma-Aldrich, America) were used as received.

\subsection{Synthesis of GO and AIGO fillers}

Graphene oxide (GO) was prepared from natural graphite by modified Hummer's method [30]. The natural graphite $(3 \mathrm{~g})$ was mixed with $\mathrm{H}_{3} \mathrm{PO}_{4}(40 \mathrm{ml})$ and $\mathrm{H}_{2} \mathrm{SO}_{4}(360 \mathrm{ml})$ in a four-neck flask, and then the temperature increased to $50^{\circ} \mathrm{C}$ followed by the slow addition of $18 \mathrm{~g}$ of $\mathrm{KMnO}_{4}$. The mixture was continuously stirred for $12 \mathrm{~h}$ and then $\mathrm{H}_{2} \mathrm{O}_{2}(8 \mathrm{ml})$ was slowly added into the mixture. The fully oxidized suspension was poured into a large amount of DI water. The GO powder was obtained after centrifuge and washing process.

The alumina covered graphene oxide (AlGO) was prepared by sol-gel reaction. Aluminum isopropoxide (AlIP) was dispersed in alcohol at $70^{\circ} \mathrm{C}$ for 30 min and followed by mixing with $\mathrm{GO}$ at $60^{\circ} \mathrm{C}$ for 1 day. Subsequently, the mixture was allowed to react at $150^{\circ} \mathrm{C}$ for $12 \mathrm{~h}$ by hydrothermal method to obtain alumina covered graphene oxide (AlGO) nanosheets. The AlGO nanosheets were vacuum-dried at $160^{\circ} \mathrm{C}[31]$. The synthesis procedure was shown in Figure 1.
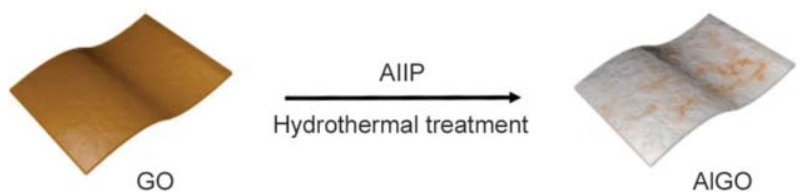

Figure 1. Schematic diagram of AlGO nanosheets derived from GO. 


\subsection{Synthesis of PI and its nanocomposite films}

PI was synthesized from ODA and IDPA via twostep method show in Figure 2. First, the ODA was dissolved in DMAc in a three neck flask and stirred at room temperature, followed by slow addition of IDPA into ODA solution, stirred for $12 \mathrm{~h}$ to obtain a PI precursor of poly(amic acid) (PAA). PI films were obtained from PAA by a thermal imidization process. Similarly, PI nanocomposite films were synthesized by adding GO and AlGO nanosheets $(0.1 \mathrm{wt} \%)$ in PAA. Subsequently, the resulting solution coated on glass substrate and underwent a thermal imidization process for $5 \mathrm{~h}$ at $250^{\circ} \mathrm{C}$ to obtain a series of PI nanocomposite films.

\subsection{Characterization of PI and PI nanocomposite films}

The functional groups of GO and AlGO were examined using a Fourier transform infrared spectrometer (JASCO FT/IR-4600). X-ray photoelectron spectrometer (XPS, ESCA PHI-1600, Physical Electronics) was performed to analyze the surface composition of fillers. A field emission scanning electron microscope (FE-SEM, JEOL JSM-7100F) was utilized at an acceleration voltage of $15 \mathrm{kV}$ to observe the morphology of GO and AlGO nanosheets fillers. A transmission electron microscope (TEM, JEOL JEM-2100F) equipped with EDS (OXFORD, XMAX) was also used at an acceleration voltage of $200 \mathrm{kV}$ to observe the morphology of fillers and their dispersion in PI matrices. Atomic force microscope (AFM, JPK Instruments, NanoWizard) with a scan rate of $1 \mathrm{~Hz}$ and scan area $40 \times 40 \mu \mathrm{m}$ was used to measure filler's thickness. The optical transmittance of each film was examined by an UV-vis spectrophotometer (JASCO V-750). A permeation test system was utilized to obtain the water vapor transmission rate (WVTR, MOCON, Permatran-W 3/61) of samples $\left(10 \mathrm{~cm}^{2}\right)$ at atmospheric pressure, $40{ }^{\circ} \mathrm{C}$ and RH $100 \%$. All the electrochemical corrosion measurements were performed using an electrochemical workstation zive sp1 (Wonatech, Korea). The area of work electrode was $1 \mathrm{~cm}^{2}$. All tests were performed at $25{ }^{\circ} \mathrm{C}$ in corrosive medium $(3.5 \mathrm{wt} \%$ sodium chloride solution). The working electrode (cold rolled steel, CRS) coated with the prepared PI nanocomposite was immersed in the corrosive medium for one hour to ensure the steady state prior to polarization current measurement. The potential was scanned from -250 to $+250 \mathrm{mV}$ at a scan rate of $2.5 \mathrm{mV} \cdot \mathrm{s}^{-1}$ for polarization current experiments. The Tafel extrapolation technique was utilized to determine the corrosion potential ( $\left.E_{\text {corr }}\right)$ and corrosion current density $\left(I_{\text {corr }}\right) . I_{\text {corr }}$ was determined by superimposing a straight line along the linear portion of cathodic or anodic curve and then extrapolating it through $E_{\text {corr }}$. The polarization resistance $\left(R_{\mathrm{p}}\right)$ value was calculated from the Tafel plots, according to the Stearn-Geary equation, as shown in Equation (1) [32, 33]:

$$
R_{\mathrm{p}}=\frac{b_{\mathrm{a}} b_{\mathrm{c}}}{2.303\left(b_{\mathrm{a}}+b_{\mathrm{c}}\right) I_{\text {corr }}}
$$

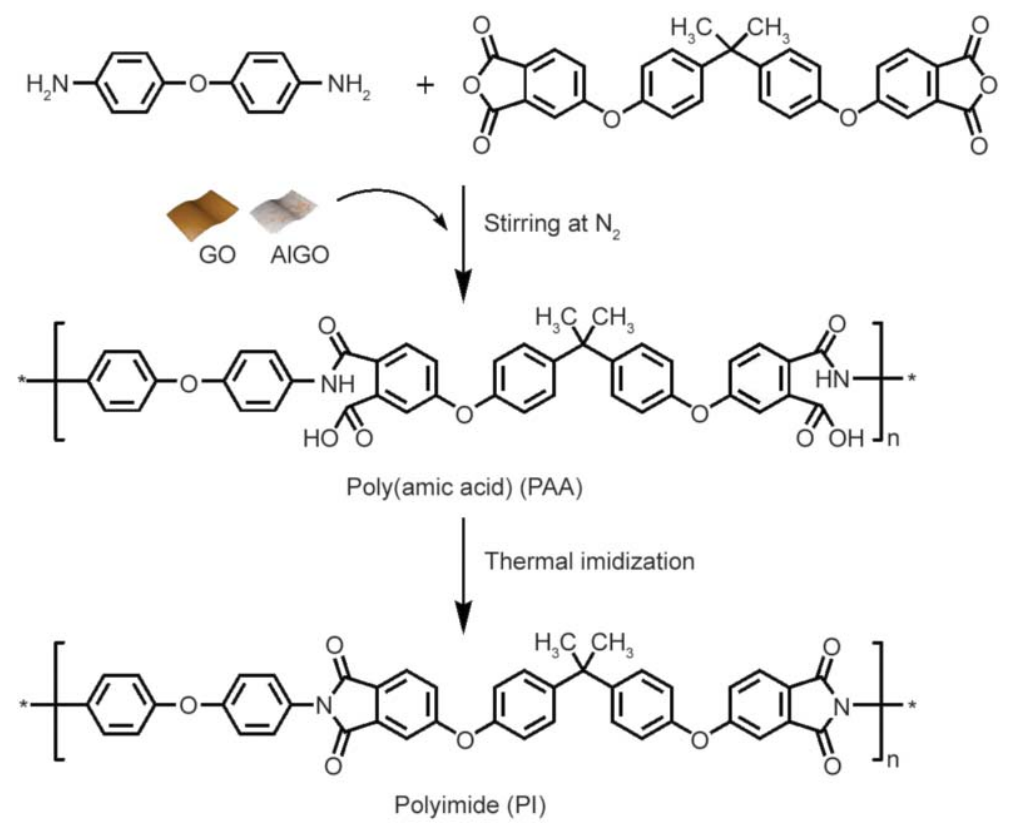

Figure 2. Preparation of PI and PI nanocomposite. 
where $b_{\mathrm{a}}$ and $b_{\mathrm{c}}$ are the anodic and cathodic Tafel slopes, respectively. Corrosion rate $(C R$ [mm per year] was calculated using Equation (2) [34, 35]:

$C R=\frac{I_{\text {corr }} \cdot M \cdot 3270}{D \cdot V}$

where $I_{\text {corr }}$ is the current density, $\left[\mathrm{A} \cdot \mathrm{cm}^{-2}\right], M$ is the molecular mass [g], $V$ is the valence (the number of electrons that lose during the oxidation reaction), and $D$ is the density of CRS $\left[\mathrm{g} \cdot \mathrm{cm}^{-3}\right]$.

\section{Results and discussion}

\subsection{Characterization of GO and AIGO filler}

Figure 3 shows the FTIR spectra of GO and AlGO in the range of $400-4000 \mathrm{~cm}^{-1}$. The spectrum of graphene oxide illustrates the $-\mathrm{OH}$ band at $3375 \mathrm{~cm}^{-1}$, carboxylic acid band at $1720 \mathrm{~cm}^{-1}, \mathrm{C}=\mathrm{C}$ band at $1620 \mathrm{~cm}^{-1}$, and $\mathrm{C}-\mathrm{OH}$ band at 1356 and $1042 \mathrm{~cm}^{-1}$ [36]. These peaks of functional groups in the GO were also found in the FTIR spectrum of AlGO, the peak positions were slightly shifted after being covered by alumina on the GO. After Al is coated on the GO surface, new peaks at 1210 and $1080 \mathrm{~cm}^{-1}$ are attributed to Al-OH flexible vibration [37]. In addition, the characteristic peak at $887 \mathrm{~cm}^{-1}$ is attributed to $\mathrm{Al}-\mathrm{OH}$ bending vibration. In addition, stretching vibration of $\mathrm{Al}-\mathrm{O}$ at $618 \mathrm{~cm}^{-1}$ and the $\mathrm{Al}-\mathrm{OH}_{2}$ band at $482 \mathrm{~cm}^{-1}$ are present [38].

The chemical structures of the coated alumina layers were determined via XPS analysis; the results are presented in Figure 4. The $\mathrm{C} 1 \mathrm{~s}$ and $\mathrm{O} 1 \mathrm{~s}$ signals for $\mathrm{GO}$ and $\mathrm{AlGO}$ appeared at 284 and $530 \mathrm{eV}$, respectively. For Al, the $2 \mathrm{~s}$ and $2 \mathrm{p}$ signals were observed at 119 and $75 \mathrm{eV}$, respectively, in the AlGO spectrum.

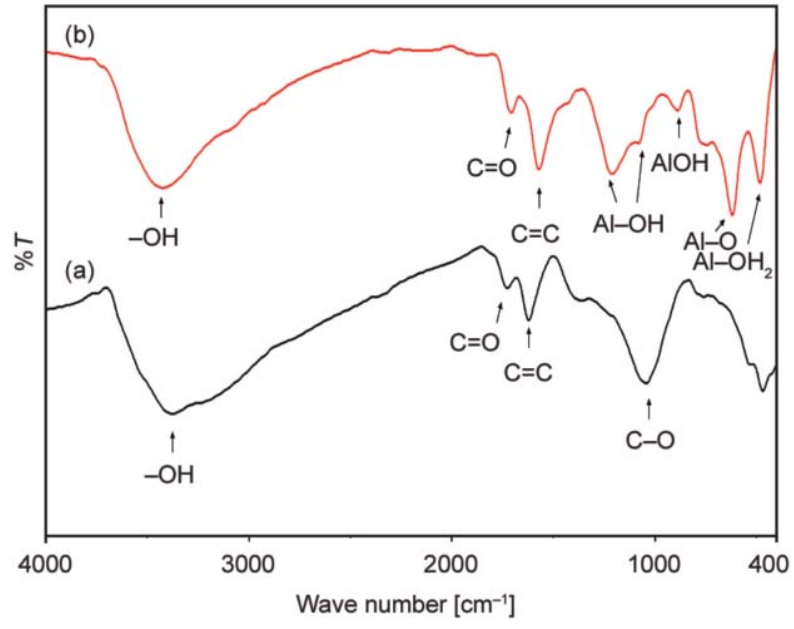

Figure 3. FTIR spectra of (a) GO and (b) AlGO.

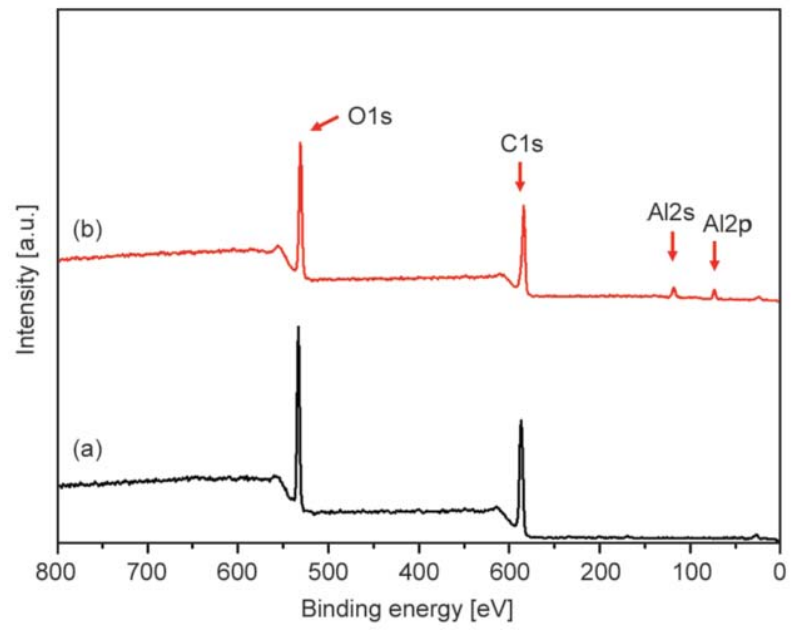

Figure 4. XPS spectra of (a) GO and (b) AlGO.

It could be seen that the atomic concentrations of $\mathrm{C} 1 \mathrm{~s}$ and $\mathrm{O} 1 \mathrm{~s}$ changed from 65.9 and $34.1 \%(\mathrm{GO})$ to 59.5 and $35.0 \%$ (AlGO), respectively. A low-intensity A12p peak with a concentration of 5.5\% was observed in the AlGO spectrum. This suggests that functional groups containing oxygen atoms are introduced to the surface of the AlGO and are associated with the newly created $\mathrm{Al}$ species [31, 39].

The FE-SEM images in Figure 5a, $5 \mathrm{~b}$ show that the GO surface was wrinkled; however, the surface of the alumina-coated GO was relatively smooth with wrinkles. The corresponding EDS analysis showed that aluminum was present in the prepared AlGO fillers. In addition, TEM images revealed the wrinkled nature of the GO surface. On the other hand, many black spots and filaments appeared on the GO surface of the AlGO fillers (Figure 5c, 5d). These results indicated that alumina layers were successfully deposited onto the surface of the GO. EDS analyses of AlGO from TEM images indicated that the $\mathrm{Al}$ and $\mathrm{O}$ content was 14.68 at $\% \mathrm{Al}$ and 31.34 at $\%$, respectively. The carbon content of AlGO was reduced to less than $53.98 \%$ as compared to $86.54 \%$ for GO. Figure $5 \mathrm{e}-5 \mathrm{~g}$ the mapping of the $\mathrm{AlGO}$ indicates that the black spots and filaments were caused by the aluminum covered the graphene oxide. This suggests that two-dimensional AlGO was successfully prepared via the hydrothermal process.

Theoretically, AlGO should be thicker than GO since GO was used as the template to synthesize the AlGO nanosheets. The thickness was directly measured by AFM observations. The AFM images and the corresponding height scan of the samples (Figure 6) showed that the thickness of the GO and AlGO was 


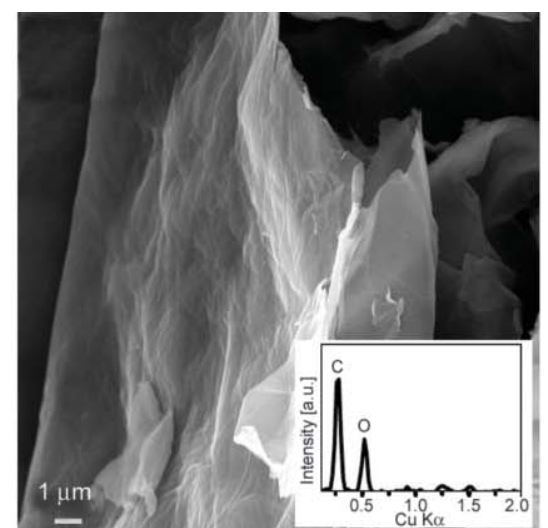

a)

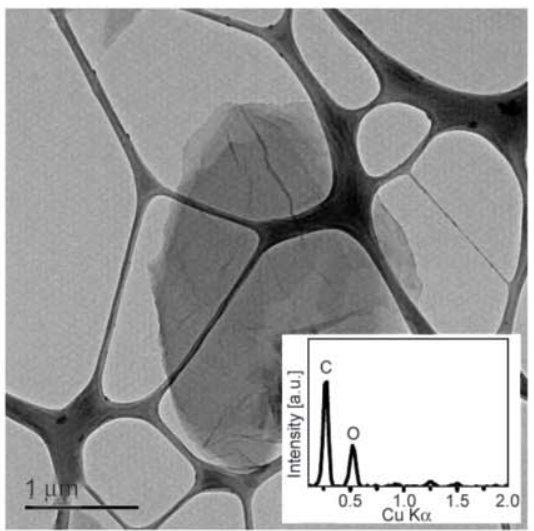

c)

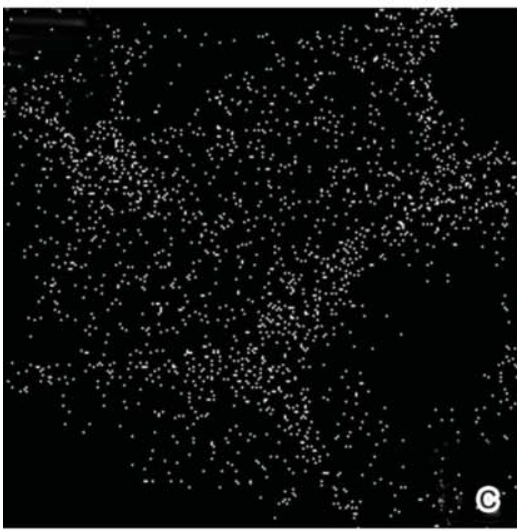

e)

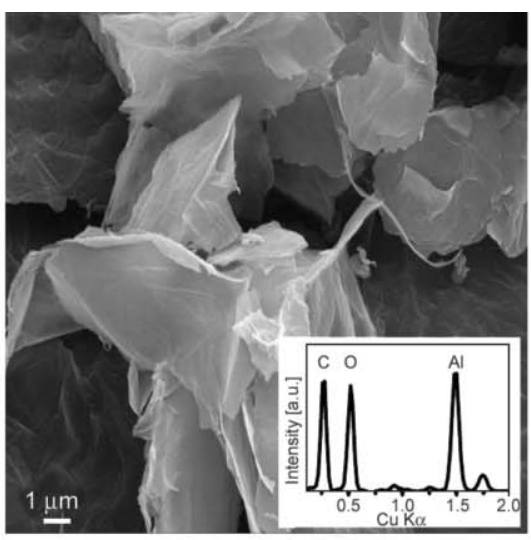

b)

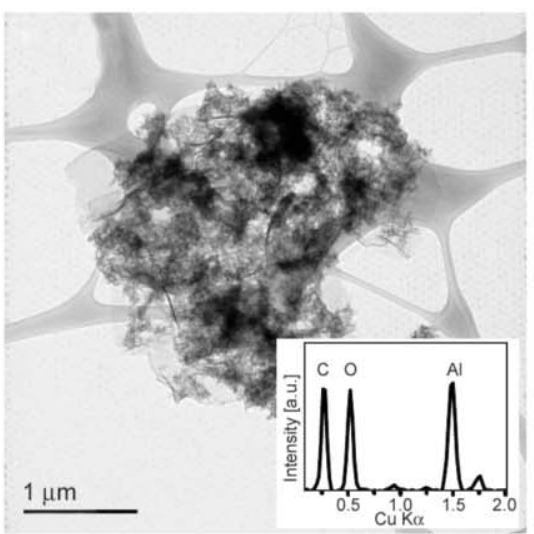

d)

Figure 5. FE-SEM images of (a) GO and (b) AlGO. TEM images of (c) GO, (d) AlGO, and (e-g) elemental mapping images. Insets: EDS results for the corresponding images.

approximately 3 and $5 \mathrm{~nm}$, respectively. The difference in thickness confirmed that the alumina layer was successfully coated on the GO surface.

\subsection{Dispersion of GO and AIGO in PI nanocomposite films}

TEM microtome images and SEM fractured crosssectional surfaces were obtained to investigate the morphology of the as-prepared nanocomposite films. Figure 7a, 7b demonstrates that AlGO was better dispersed in the PI matrix than GO, and that there was an aggregation of GO in the GO/PI nanocomposite.
However, the fractured cross-sectional surfaces of the GO/PI and AlGO/PI nanocomposites were smooth, and no sign of aggregation of GO or AlGO fillers was observed Figure $7 \mathrm{c}-7 \mathrm{e}$. The adhesion between the fillers and PI was strong, so most of the GO or AlGO sheets remained in the PI matrix after the cryostat fraction. However, some of the sheets were pulled out, which created holes in the PI matrix, as shown in Figure 7e, 7d. This phenomenon influences the optical transparency, moisture barrier, and anticorrosion properties of the nanocomposites [40]. 

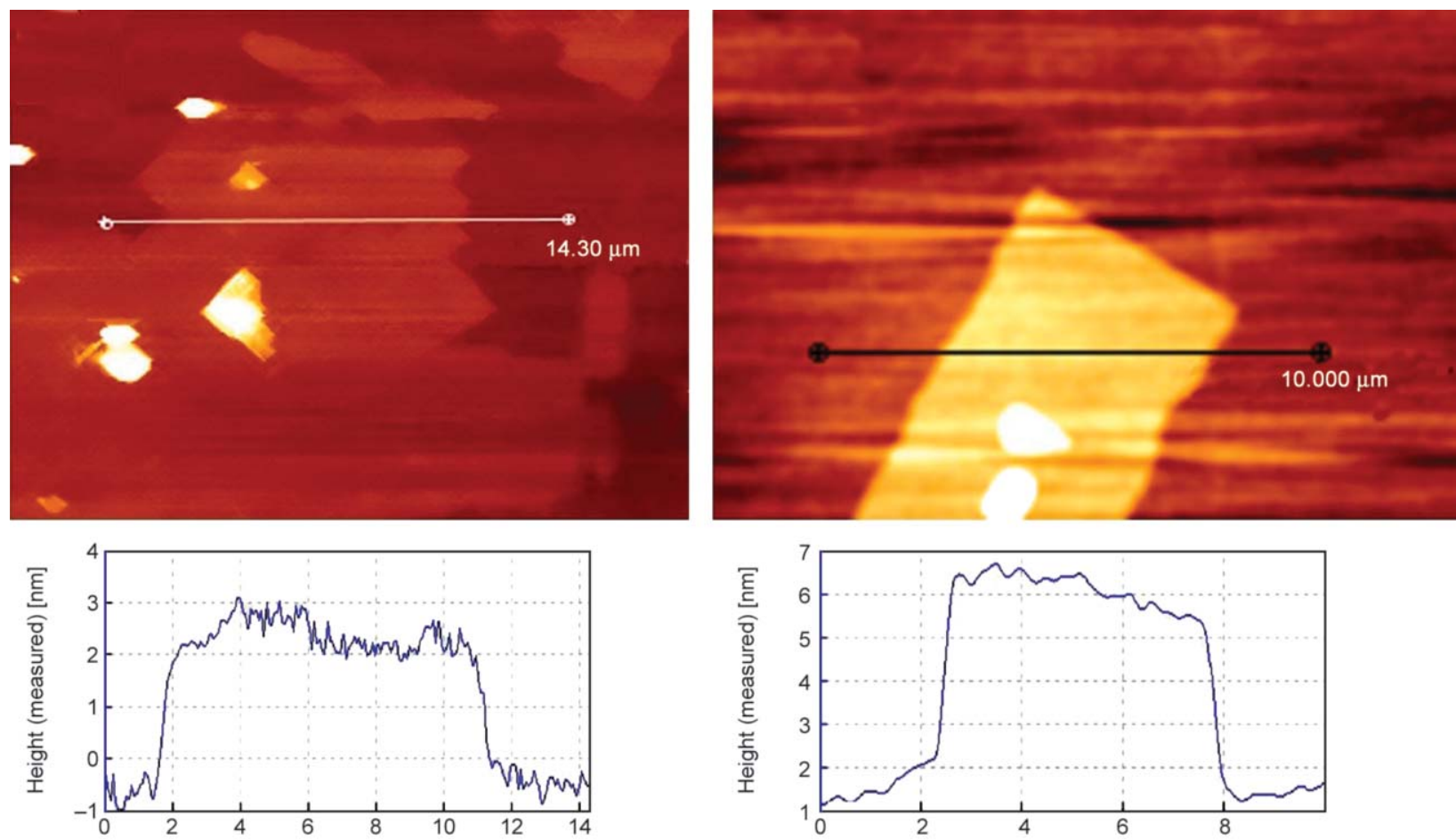

a)

Offset [ $\mu \mathrm{m}]$

b)

Offset [ $\mu \mathrm{m}]$

Figure 6. AFM image and height scan of the indicated line of (a) GO and (b) AlGO.

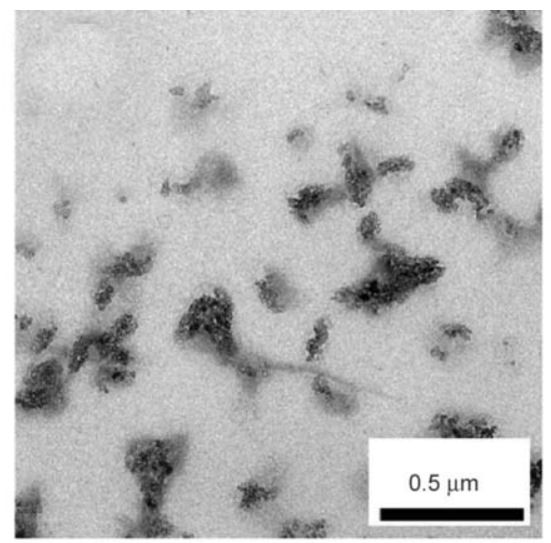

a)

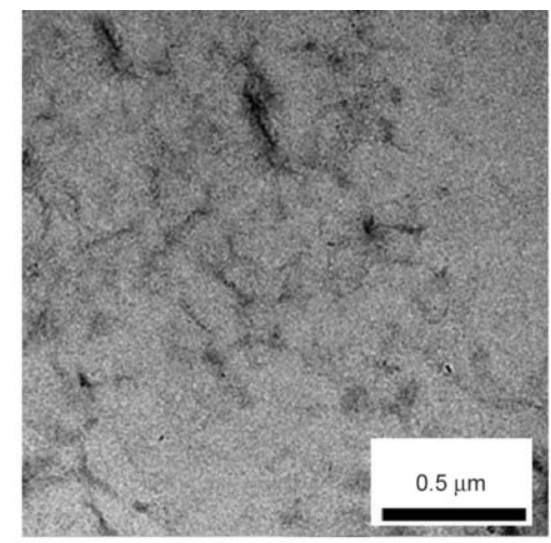

b)

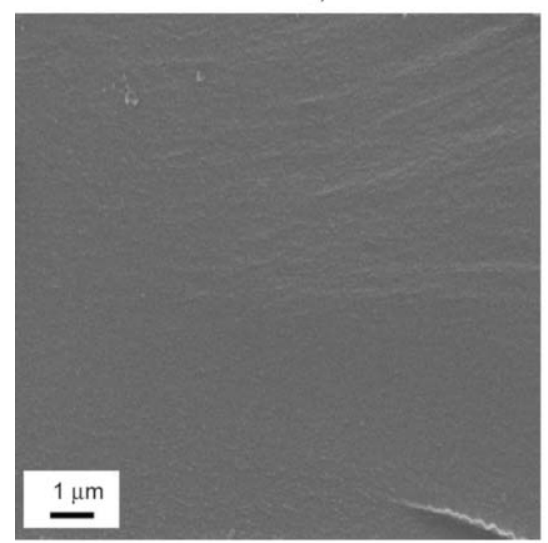

c)

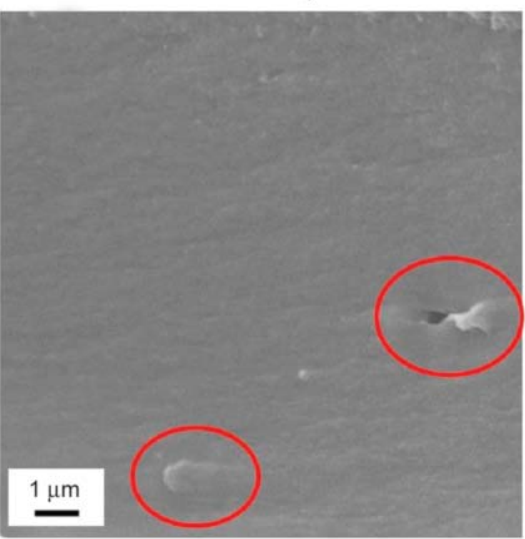

d)

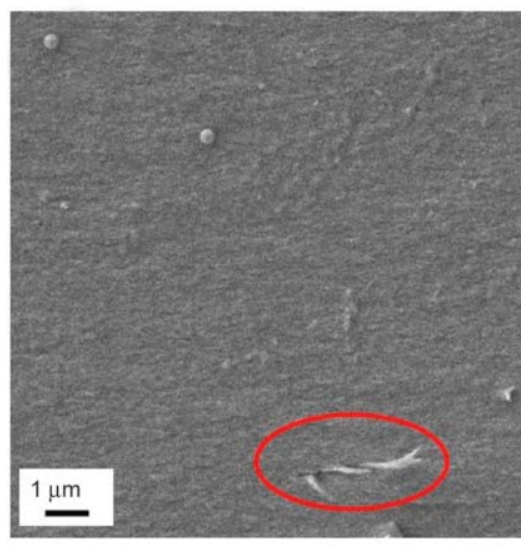

e)

Figure 7. TEM images of (a) GO/PI and (b) AlGO/PI nanocomposite films. SEM images of the fractured surface of (c) PI, (d) GO/PI, and (e) AlGO/PI nanocomposite films. 


\subsection{Optical transparency of pure PI and PI nanocomposite films}

The optical properties of PI nanocomposite films coated on optical glass with an average thickness of $35 \mu \mathrm{m}$ were evaluated by ultraviolet-visible (UV-vis) spectroscopy. Figure 8 shows the UV-vis spectra of pure PI and PI nanocomposite films containing $0.1 \mathrm{wt} \%$ of GO or AlGO. The transmittance of the pure PI film at $550 \mathrm{~nm}$ was approximately $80 \%$. When GO was incorporated into the PI film, the optical transparency of the resulting GO/PI film was reduced to $70.19 \%$. GO is a black powder, so the white AlGO powder dispersed in the PI film maintained better transmittance $(>75 \%)$. The transparent properties of the AlGO/PI nanocomposite indicated that the nanocomposite has significant potential for application as an electronic device coating.

\subsection{Barrier properties of PI nanocomposite films}

For anticorrosion applications, coatings should prevent or at least mitigate moisture transfer between the metal and the surroundings, and the WVTR should be as low as possible. The following are the typical corrosion reactions of iron metal in Equations (3)-(6) [41, 42]:

$\mathrm{Fe} \rightarrow \mathrm{Fe}^{2+}+2 \mathrm{e}^{-}$

$$
\begin{aligned}
& \mathrm{Fe}^{2+} \rightarrow \mathrm{Fe}^{3+}+1 \mathrm{e}^{-} \\
& \mathrm{O}_{2(\mathrm{~g})}+2 \mathrm{H}_{2} \mathrm{O}+4 \mathrm{e}^{-} \rightarrow 4 \mathrm{OH}^{-} \\
& 2 \mathrm{Fe}^{2+}{ }_{(\mathrm{aq})}+\mathrm{O}_{2(\mathrm{~g})}+2 \mathrm{H}_{2} \mathrm{O} \rightarrow 2 \mathrm{FeOOH}+2 \mathrm{H}^{+}
\end{aligned}
$$

The above equations show that sufficient amounts of $\mathrm{H}_{2} \mathrm{O}$ and $\mathrm{O}_{2}$ are required for the formation of rust and for the dissolution of corrosion-causing components. If any of these reactions are prevented, corrosion can be inhibited, and the coating will be effective for corrosion prevention. Therefore, it is reasonable to assume that increasing the difficulty of the diffusion pathway will effectively prevent $\mathrm{H}_{2} \mathrm{O}$ and $\mathrm{O}_{2}$ from accessing the substrate surface, leading to good anticorrosion properties of the coating.

Recently, many studies have shown that nanofiller can effectively enhance the barrier properties of various polymers [14, 43-46]. This is because their morphologies have high aspect ratios that lengthen the diffusion pathways for moisture or oxygen, leading to improved barrier properties [47, 48].

The barrier properties of selected nanocomposites are listed in Figure 9. The clay/polymer film exhibited better water barrier properties than the $\mathrm{SiO}_{2} /$ polymer. Yeh and coworkers improved the high aspect ratio of graphene $(>500)$ and dispersed it effectively within the polymer, thus enhancing the WVTR compared to that of clay/polymer [14].

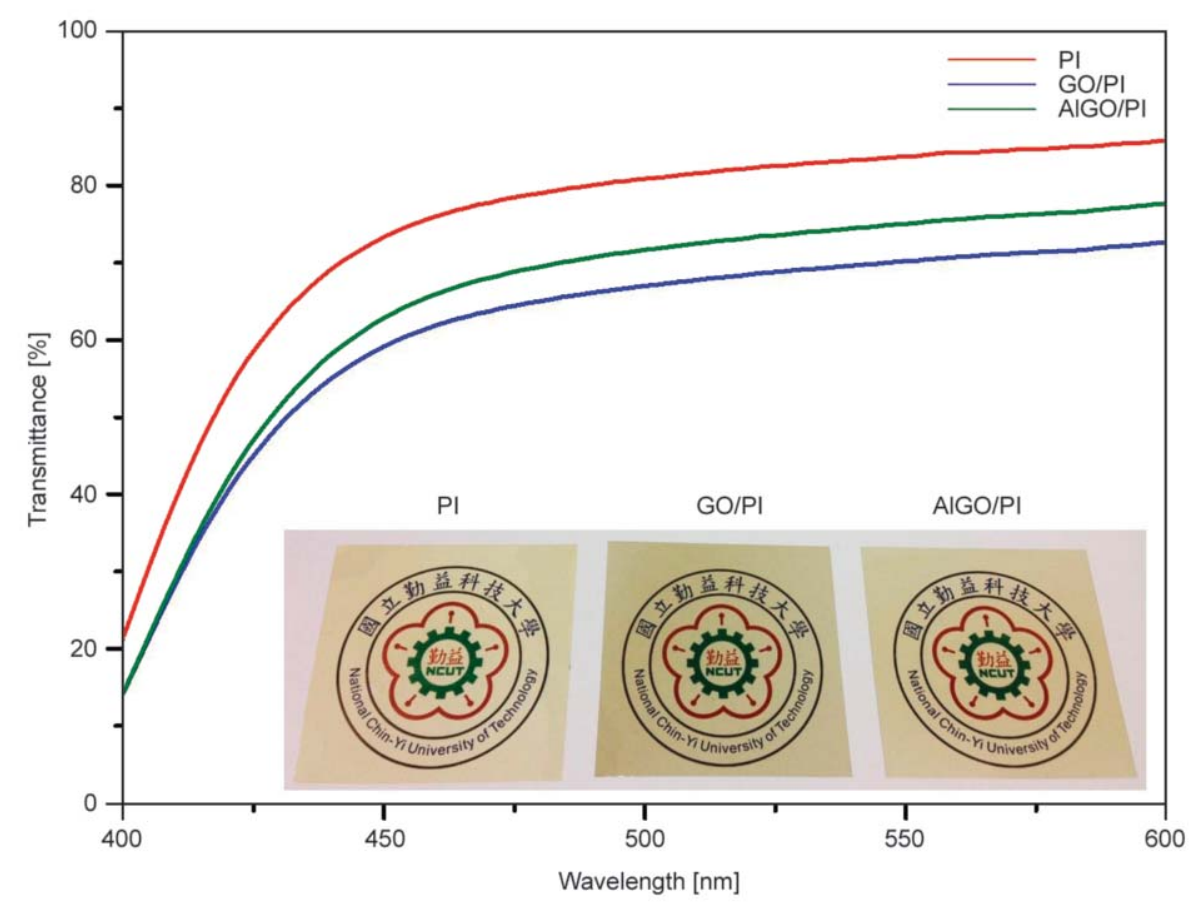

Figure 8. UV-vis spectra of (a) pure PI, (b) GO/PI, and (c) AlGO/PI nanocomposite films with an average thickness of $35 \mu \mathrm{m}$ in the visible light region. 
In our study, the WVTR of the pure PI film was determined to be approximately $140 \mathrm{~g} /\left(\mathrm{m}^{2}\right.$.day $)$ and

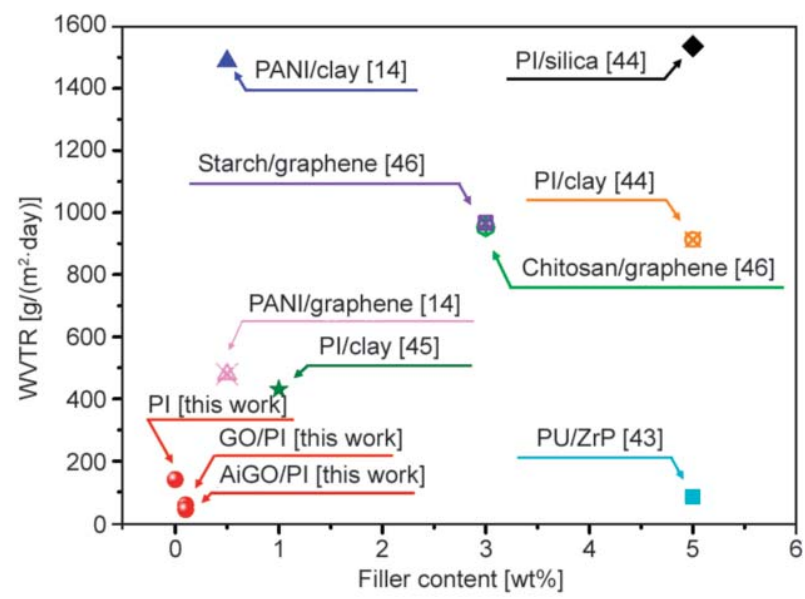

Figure 9. WVTR values of PI and PI nanocomposite films, along with the values for other polymeric nanocomposites from literature [14, 43-46]. decreased with increasing amounts of fillers in PI (Figure 9). The WVTRs of the PI-based nanocomposites upon blending $0.1 \mathrm{wt} \%$ of GO and AlGO were approximately 58 and $43 \mathrm{~g} /\left(\mathrm{m}^{2} \cdot\right.$ day $)$, respectively.

\subsection{Potentiodynamic measurements of PI nanocomposite films}

A series of PI and PI nanocomposites coated on CRS electrodes were tested to evaluate their anticorrosion effects. The corrosion potential $\left(E_{\text {corr }}\right)$, corrosion current $\left(I_{\text {corr }}\right)$, polarization resistance $\left(R_{\mathrm{p}}\right)$, anodic Tafel slope $\left(b_{\mathrm{a}}\right)$, cathodic Tafel slope $\left(b_{\mathrm{c}}\right)$, and corrosion rate $(C R)$ of the prepared samples are summarized in Tables 1 and 2. In theory, higher values of $E_{\text {corr }}$ and $R_{\mathrm{p}}$, as well as lower values of $I_{\text {corr }}$ and $C R$, indicate better corrosion protection $[49,50]$. The potentiodynamic polarization curves for the PI

Table 1. The electrochemical properties of PI and PI nanocomposite films after 1 day immersion in salt solution.

\begin{tabular}{|l|c|c|c|c|c|c|}
\hline \multicolumn{1}{|c|}{ Sample } & \multicolumn{7}{c|}{ Electrochemical measurements } \\
\hline & $\begin{array}{c}\boldsymbol{E}_{\text {corr }} \\
{[\mathbf{m V}]}\end{array}$ & $\begin{array}{c}\boldsymbol{I}_{\text {corr }} \\
{\left[\mathbf{A} \cdot \mathbf{c m}^{-2}\right]}\end{array}$ & $\begin{array}{c}\boldsymbol{R}_{\mathbf{p}} \\
{\left[\mathbf{k} \boldsymbol{\Omega} \cdot \mathbf{c m}^{2}\right]}\end{array}$ & $\begin{array}{c}\boldsymbol{C R} \\
{[\mathbf{m m} / \mathbf{y e a r}]}\end{array}$ & $\boldsymbol{b}_{\mathbf{a}}$ & $\boldsymbol{b}_{\mathbf{c}}$ \\
\hline Bare & $-764 \pm 11.2$ & $(5.78 \pm 0.26) \cdot 10^{-5}$ & $0.27 \pm 0.15$ & $6.77 \cdot 10^{-1}$ & $0.520 \pm 0.008$ & $0.085 \pm 0.007$ \\
\hline $\mathrm{PI}$ & $-612 \pm 7.7$ & $(4.10 \pm 0.08) \cdot 10^{-7}$ & $95.08 \pm 0.126$ & $4.80 \cdot 10^{-3}$ & $0.169 \pm 0.003$ & $0.191 \pm 0.004$ \\
\hline $\mathrm{GO} / \mathrm{PI}$ & $-310 \pm 4.6$ & $(1.08 \pm 0.05) \cdot 10^{-8}$ & $2.93 \cdot 10^{3} \pm 112$ & $1.26 \cdot 10^{-4}$ & $0.202 \pm 0.003$ & $0.114 \pm 0.003$ \\
\hline $\mathrm{AlGO} / \mathrm{PI}$ & $-213 \pm 4.3$ & $(3.44 \pm 0.05) \cdot 10^{-9}$ & $1.34 \cdot 10^{4} \pm 95$ & $4.03 \cdot 10^{-5}$ & $0.151 \pm 0.002$ & $0.134 \pm 0.003$ \\
\hline
\end{tabular}

Table 2. The electrochemical properties of PI nanocomposite films after 30 day immersion in salt solution.

\begin{tabular}{|l|c|c|c|c|c|c|}
\hline \multicolumn{1}{|c|}{ Sample } & \multicolumn{6}{c|}{ Electrochemical measurements } \\
\hline & $\begin{array}{c}\boldsymbol{E}_{\text {corr }} \\
{[\mathbf{m V}]}\end{array}$ & $\begin{array}{c}\boldsymbol{I}_{\text {corr }} \\
{\left[\mathbf{A} \cdot \mathbf{c m}^{-2}\right]}\end{array}$ & $\begin{array}{c}\boldsymbol{R}_{\mathbf{p}} \\
{\left[\mathbf{k} \boldsymbol{\cdot} \cdot \mathbf{c m}^{2}\right]}\end{array}$ & $\begin{array}{c}\boldsymbol{C R} \\
{[\mathbf{m m} / \mathbf{y e a r}]}\end{array}$ & $\boldsymbol{b}_{\mathbf{a}}$ & $\boldsymbol{b}_{\mathbf{c}}$ \\
\hline $\mathrm{PI}$ & $-739 \pm 24.3$ & $(4.16 \pm 0.35) \cdot 10^{-7}$ & $75 \pm 0.22$ & $4.87 \cdot 10^{-3}$ & $0.241 \pm 0.006$ & $0.103 \pm 0.011$ \\
\hline $\mathrm{GO} / \mathrm{PI}$ & $-533 \pm 20.5$ & $(1.73 \pm 0.21) \cdot 10^{-7}$ & $222 \pm 0.18$ & $2.02 \cdot 10^{-4}$ & $0.182 \pm 0.008$ & $0.171 \pm 0.006$ \\
\hline $\mathrm{AlGO} / \mathrm{PI}$ & $-242 \pm 15.0$ & $(8.79 \pm 0.12) \cdot 10^{-9}$ & $3708 \pm 0.17$ & $1.03 \cdot 10^{-4}$ & $0.167 \pm 0.003$ & $0.136 \pm 0.005$ \\
\hline
\end{tabular}
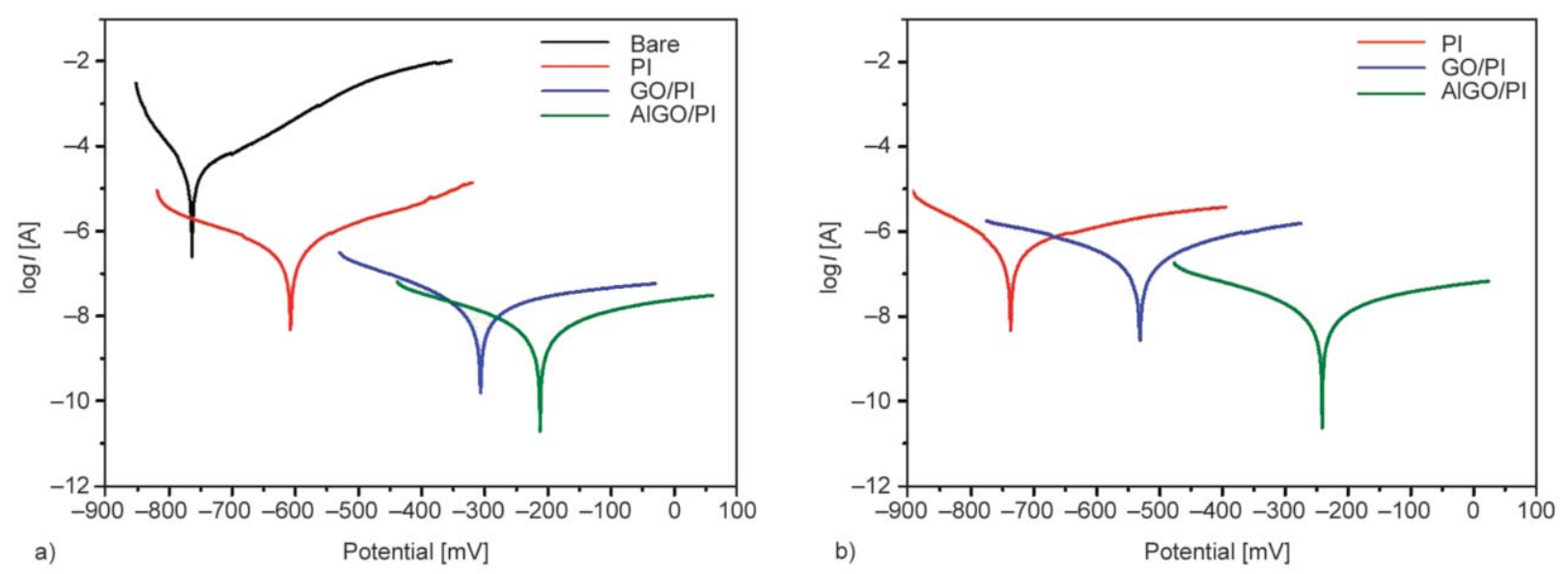

Figure 10. Tafel plots of PI and PI nanocomposite films immersed in $3.5 \mathrm{wt} \%$ aqueous $\mathrm{NaCl}$ solution for (a) 1 day and (b) 30 days. 
and PI nanocomposite coatings are shown in Figure 10 . The $I_{\text {corr }}$ and $E_{\text {corr }}$ values of neat CRS were $5.78 \cdot 10^{-5} \mathrm{~A} \cdot \mathrm{cm}^{-2}$ and $-764 \mathrm{mV}$, respectively. After coating with the PI film, $I_{\text {corr }}$ decreased to $4.10 \cdot 10^{-7} \mathrm{~A} \cdot \mathrm{cm}^{-2}$, indicating a protective effect of the PI coating. The incorporation of $\mathrm{GO}$ and $\mathrm{AlGO}$ into the PI matrix led to lower $I_{\text {corr }}$ values of $1.08 \cdot 10^{-8}$ and $3.44 \cdot 10^{-9} \mathrm{~A} \cdot \mathrm{cm}^{-2}$, respectively, and higher $E_{\mathrm{corr}}$ values of -310 and $-213 \mathrm{mV}$, respectively.

To further study the long-term anticorrosion properties of the coating materials, the samples were immersed in a $3.5 \mathrm{wt} \% \mathrm{NaCl}$ solution for 30 days. $I_{\text {corr }}$ and $E_{\text {corr }}$ of the AlGO/PI coating shifted only from $3.44 \cdot 10^{-9}$ to $8.79 \cdot 10^{-9} \mathrm{~A} \cdot \mathrm{cm}^{-2}$ and from -213 to $-242 \mathrm{mV}$, respectively. However, $E_{\text {corr }}$ of the GO/PI and PI coatings dramatically decreased from -310 to $-533 \mathrm{mV}$ and from -612 to $-739 \mathrm{mV}$, respectively. Similarly, the AlGO/PI coatings showed the lowest value of $I_{\text {corr }}$ compared to the GO/PI coatings. These results indicate that the $\mathrm{AlGO} / \mathrm{PI}$ coating possesses better anticorrosion properties than the GO/PI coating.

The superior anticorrosion performance can be attributed to the insulating layer of alumina on GO, which
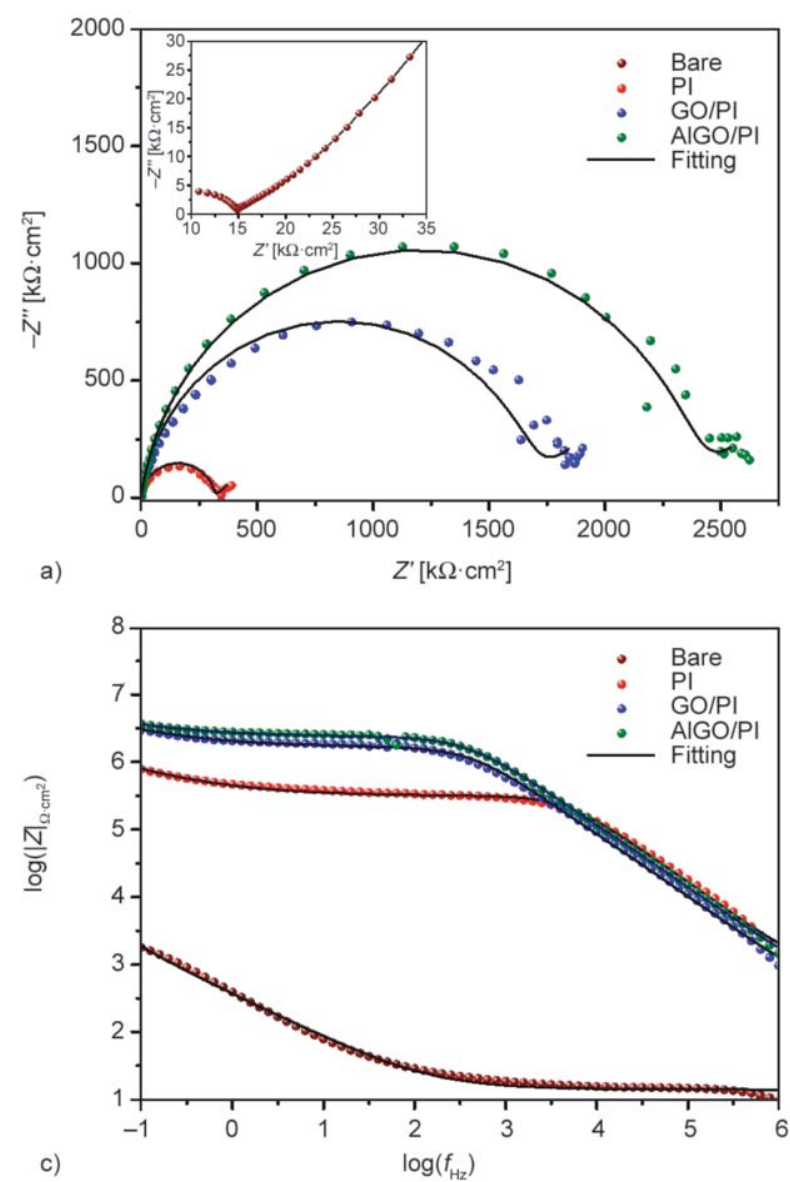

isolates the electron transfer pathways between the GO and CRS metals, thus inhibiting the corrosionpromotion activity of the graphene [51, 52].

\subsection{Electrochemical impedance spectroscopy (EIS) of PI nanocomposite films}

EIS was used to investigate the effect of the addition of GO and AlGO on the barrier and corrosion protection properties of the PI coatings in a $3.5 \mathrm{wt} \% \mathrm{NaCl}$ solution after 1 day of immersion. The Nyquist plots of the samples were almost semicircular, as shown in Figure 11a. The high-frequency region of the capacitive arc reflected the properties of the coating, while the low-frequency region of the capacitive arc reflected the corrosion of the substrate. The long-term anticorrosion properties were also examined by immersing the samples in $3.5 \mathrm{wt} \% \mathrm{NaCl}$ solutions for 30 days. As shown in Figure 11b, the capacitive arcs of the PI and GO/PI decreased significantly in the high-frequency region. This result means that the protective effect of the coatings was declining. The capacitive arc of $\mathrm{AlGO} / \mathrm{PI}$ was larger than that for the other coatings, suggesting a better anticorrosion property.
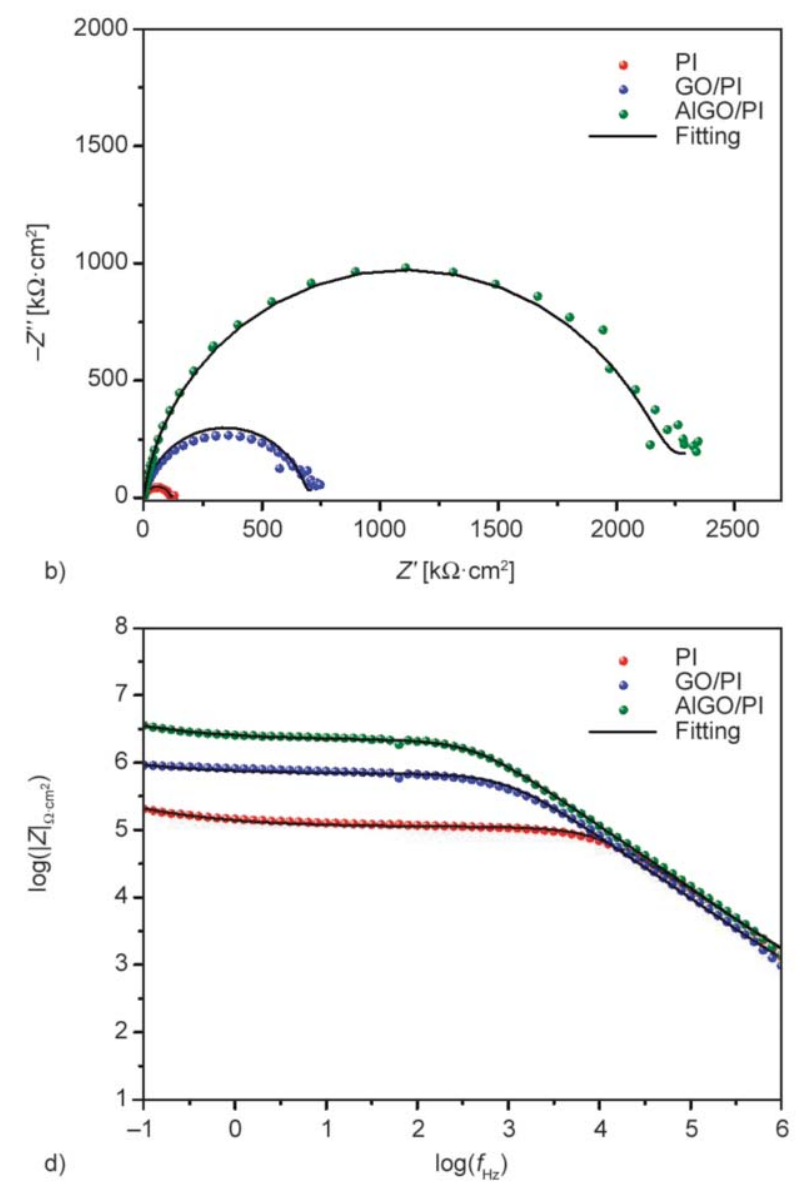

Figure 11. (a, b) Nyquist plots and (c, d) Bode plots of PI and PI nanocomposites films immersed in $3.5 \mathrm{wt} \%$ aqueous $\mathrm{NaCl}$ solution for (a, c) 1 day, (b, d) 30 days. The inset in (a) shows the Nyquist plot of neat CRS. 
Bode plots of the PI and PI nanocomposites are shown in Figure 11c, 11d. In general, the lower-frequency region of the Bode impedance was used to assess the overall corrosion resistance of the uncoated and coated samples. After 1 day of immersion, the $|Z|_{0.1 \mathrm{~Hz}}$ values for the bare, PI, GO/PI, and AlGO/PI samples were $1.88,796,3050$, and $3660 \mathrm{k} \Omega \cdot \mathrm{cm}^{2}$, respectively. These values of the coatings were significantly higher than that for the bare sample, implying a good initial inhibited performance of the coatings. After 30 days of immersion, the $|Z|_{0.1 \mathrm{~Hz}}$ values for the PI, GO/PI, and AlGO/PI samples decreased to 209,928 , and $3650 \mathrm{k} \Omega \cdot \mathrm{cm}^{2}$, respectively. These results indicated a decrease in the barrier performance owing to the corroding medium through the defects and pores of the coating. The AlGO/PI composite coating still showed the highest $|Z|_{0.1 \mathrm{~Hz}}$ value. This was because the insulating material, $\mathrm{Al}_{2} \mathrm{O}_{3}$, coated on graphene obstructed the electron pathways for the galvanic corrosion of the graphene-metal couple [53]. Schematics of the corrosion prevention mechanism of the PI composites and an electrical equivalent circuit are shown in Figure 12a. The EIS results were fitted to different equivalent circuit models by analyzing the Nyquist plots. The model revealed the electrolyte solution resistance $\left(R_{\mathrm{s}}\right)$, coating resistance $\left(R_{\mathrm{c}}\right)$, and coating capacitance $\left(C_{\mathrm{c}}\right)$. Theoretical$\mathrm{ly}$, the corrosion process consists of three steps. First, electrolyte solution damages the film surface but not the steel surface. Second, a corrosion reaction occurs as the electrolyte solution reaches the steel surface. At the same time, electrons transmit through the GO and AlGO surfaces, and reduction-oxidation reactions occur. Finally, rust is generated at the coating

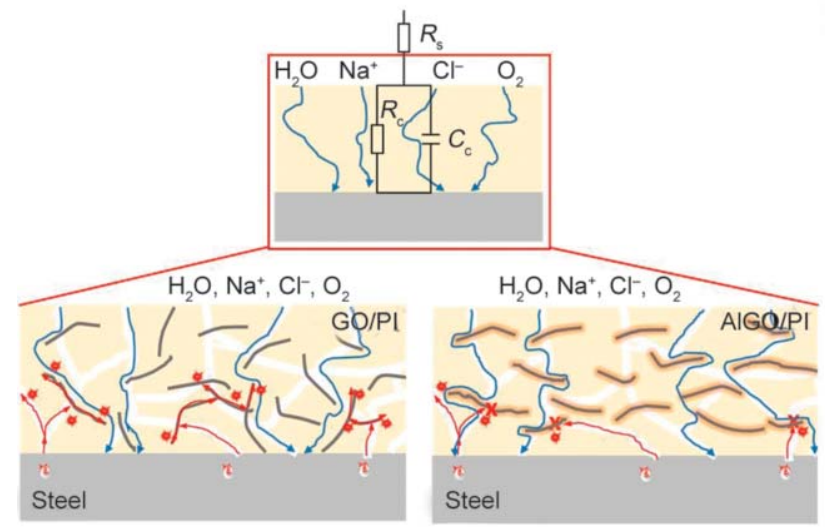

a) interface $[51,53,54]$. If there are pores in the coating, the corrosion process may be accelerated. Thus, long-term anticorrosion behavior plays a key role in the corrosion process. Figure 12a illustrates that electrons can pass through $\mathrm{GO}$, and the transfer of electrons between $\mathrm{GO}$ and the matrix accelerates the corrosion of the steel. After 30 days, compared with the initial period of immersion, $R_{\mathrm{c}}$ of all samples decreased owing to the defects of the coatings. The $R_{\mathrm{c}}$ value of the AlGO/PI coating was $2177 \mathrm{k} \Omega \cdot \mathrm{cm}^{2}$ (Figure $12 \mathrm{~b}$ ), which was the highest among all of the samples, indicating the best protective effect for CRS.

Therefore, the AlGO/PI coating exhibited better anticorrosion properties than GO/PI, which is attributed to the insulating layer of alumina on the GO surface. The alumina layer can prevent electron tunneling, thereby increasing the corrosion resistance $[55,56]$.

\section{Conclusions}

AlGO nanosheets were successfully fabricated by a sol-gel method. GO and AlGO nanosheets were characterized and homogeneously dispersed in a PI matrix. The barrier properties and corrosion protection performance of the GO/PI and AlGO/PI nanocomposite films were evaluated. The AlGO nanosheets exhibited high capability for enhancement of the corrosion resistance of the PI coatings. The excellent anticorrosion properties of $\mathrm{AlGO}$ were attributed to its nanosheet structure, which was effective in isolating the electron transfer pathways between the GO and CRS metals. Hence, a sheetlike structure, such as that of the AlGO nanosheets, is promising for application as a polymer-based anticorrosive coating.

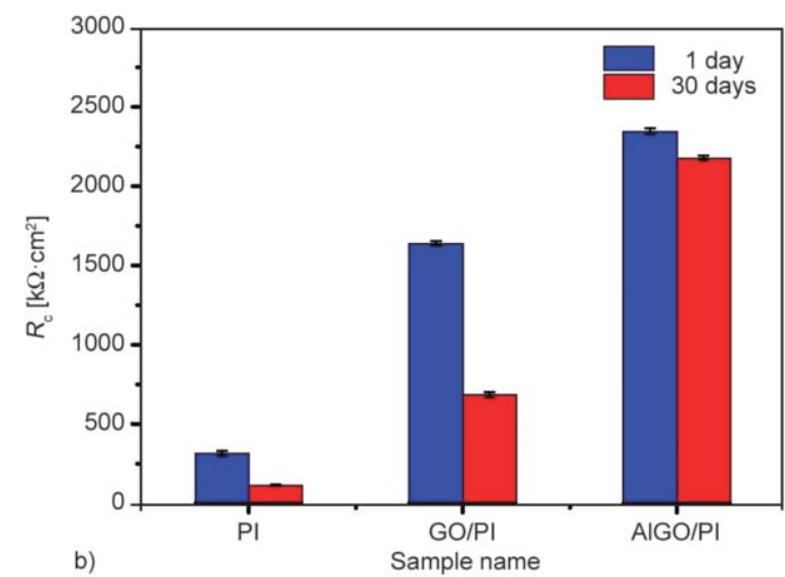

Figure 12. (a) Equivalent electric circuits and schematic of the corrosion prevention mechanism of PI nanocomposites. (b) Coating resistance $\left(R_{\mathrm{c}}\right)$ values of PI and PI composites coatings immersed in $3.5 \mathrm{wt} \% \mathrm{NaCl}$ solution for 1 or 30 days. 


\section{Acknowledgements}

This research was supported by the Ministry of Science and Technology, Taiwan under grant number MOST105-2221E-167 -033 and MOST106-2221-E-167 -033. We thank Prof. Cheng-An J. Lin, Chung Yuan Christian University (Department of Biomedical Engineering) and Prof. Jyh-Wei Lee, Ming Chi University of Technology (Department of Materials Engineering) for their help with AFM measurement.

\section{References}

[1] Huang T-C., Yeh J-M., Lai C-Y.: Polymer nanocomposite coatings. in 'Advances in polymer nanocomposites' (ed.: Gao F.) Woodhead, Oxford, 605-638 (2012). https://doi.org/10.1533/9780857096241.3.605

[2] Huang H-Y., Huang T-C., Yeh T-C., Tsai C-Y., Lai C-L., Tsai M-H., Yeh J-M., Chou Y-C.: Advanced anticorrosive materials prepared from amine-capped aniline trimer-based electroactive polyimide-clay nanocomposite materials with synergistic effects of redox catalytic capability and gas barrier properties. Polymer, 52, 23912400 (2011).

https://doi.org/10.1016/j.polymer.2011.03.030

[3] Chiu C-W., Huang T-K., Wang Y-C., Alamani B. G., Lin J-J.: Intercalation strategies in clay/polymer hybrids. Progress in Polymer Science, 39, 443-485 (2014). https://doi.org/10.1016/j.progpolymsci.2013.07.002

[4] Ji W. F., Li C. W., Huang W. J., Yu H. K., Chen R. D., Yu Y. H., Yeh J. M., Tang W. C., Su Y. C.: Composite coating with synergistic effect of biomimetic epoxy thermoset morphology and incorporated superhydrophobic silica for corrosion protection. Express Polymer Letters, 10, 950-963 (2016).

https://doi.org/10.3144/expresspolymlett.2016.88

[5] Zhou C., Lu X., Xin Z., Liu J., Zhang Y.: Polybenzoxazine/ $\mathrm{SiO}_{2}$ nanocomposite coatings for corrosion protection of mild steel. Corrosion Science, 80, 269-275 (2014). https://doi.org/10.1016/j.corsci.2013.11.042

[6] Lu H-T., Tsai M-H., Tseng I. H., Chen C-J., Huang S-L.: Morphology, thermal properties, hydrophobicity and $\mathrm{O}_{2} / \mathrm{N}_{2}$ gas separation performance of $4,4^{\prime}$-oxydiphthalic anhydride-based polyimide/titania hybrids. Polymer International, 61, 1136-1143 (2012).

https://doi.org/10.1002/pi.4191

[7] Malav J. K., Rathod R., Umare S., Patil A. Ghugal S.: Production, measurements and anticorrosion properties of electroactive polyimide/tin oxide nanocomposites. Materials Research Express, 6, Article Number: 065306 (2019). https://doi.org/10.1088/2053-1591/ab0925

[8] Tsai M-H., Tseng I. H., Chiang J-C., Li J-J.: Flexible polyimide films hybrid with functionalized boron nitride and graphene oxide simultaneously to improve thermal conduction and dimensional stability. ACS Applied Materials \& Interfaces, 6, 8639-8645 (2014). https://doi.org/10.1021/am501323m
[9] Li J-L., Yin J-H., Ji T., Feng Y., Liu Y-Y., Zhao H., Li Y-P., Zhu C-C., Yue D., Su B., Liu X-X.: Microstructure evolution effect on high-temperature thermal conductivity of LDPE/BNNS investigated by in-situ SAXS. Materials Letters, 234, 74-78 (2019).

https://doi.org/10.1016/j.matlet.2018.09.061

[10] Wong M., Ishige R., White K. L., Li P., Kim D., Krishnamoorti R., Gunther R., Higuchi T., Jinnai H., Takahara A., Nishimura R., Sue H-J.: Large-scale self-assembled zirconium phosphate smectic layers via a simple spraycoating process. Nature Communications, 5, 35893600 (2014).

https://doi.org/10.1038/ncomms4589

[11] Li S., Zhao C., Gou H., Li Y., He X., Ling Z.: Advanced anticorrosion coatings prepared from polybenzoxazine/ $\alpha$-zirconium phosphate nanocomposites. International Journal of Electrochemical Science, 13, 2661-2675 (2018).

https://doi.org/10.20964/2018.03.76

[12] Liu Y., Yin J., Liu X., Zhao X., Chen M., Li J., Zhao H., Zhu C., Su B.: Fabrication of polymer composite films with carbon composite nanofibers doped MWNTs-OH for multilevel memory device application. Composites Part B: Engineering, 156, 252-258 (2019).

https://doi.org/10.1016/j.compositesb.2018.08.045

[13] Tseng I-H., Tsai M-H., Chung C-W.: Flexible and transparent polyimide films containing two-dimensional alumina nanosheets templated by graphene oxide for improved barrier property. ACS Applied Materials and Interfaces, 6, 13098-13105 (2014).

https://doi.org/10.1021/am502962b

[14] Chang C-H., Huang T-C., Peng C-W., Yeh T-C., Lu H-I., Hung W-I., Weng C-J., Yang T-I., Yeh J-M.: Novel anticorrosion coatings prepared from polyaniline/ graphene composites. Carbon, 50, 5044-5051 (2012). https://doi.org/10.1016/j.carbon.2012.06.043

[15] Li P., Huang T-C., White K. L., Hawkins S., Kotaki M., Nishimura R., Sue H-J.: Spray-coated epoxy barrier films containing high aspect ratio functionalized graphene nanosheets. RSC Advances, 5, 102633-102642 (2015). https://doi.org/10.1039/C5RA15363H

[16] Li P., He X., Huang T-C., White K. L., Zhang X., Liang H., Nishimura R., Sue H-J.: Highly effective anti-corrosion epoxy spray coatings containing self-assembled clay in smectic order. Journal of Materials Chemistry A, 3, 2669-2676 (2015). https://doi.org/10.1039/C4TA06221C

[17] Chen S., Brown L., Levendorf M., Cai W., Ju S-Y., Edgeworth J., Li X., Magnuson C. W., Velamakanni A., Piner R. D., Kang J., Park J., Ruoff R. S.: Oxidation resistance of graphene-coated $\mathrm{Cu}$ and $\mathrm{Cu} / \mathrm{Ni}$ alloy. ACS Nano, 5, 1321-1327 (2011). https://doi.org/10.1021/nn103028d

[18] Compton O. C., Kim S., Pierre C., Torkelson J. M., Nguyen S. T.: Crumpled graphene nanosheets as highly effective barrier property enhancers. Advanced Materials, 22, 4759-4763 (2010). https://doi.org/10.1002/adma.201000960 
[19] Schriver M., Regan W., Gannett W. J., Zaniewski A. M., Crommie M. F., Zettl A.: Graphene as a long-term metal oxidation barrier: Worse than nothing. ACS Nano, 7, 5763-5768 (2013).

https://doi.org/10.1021/nn4014356

[20] Sun W., Wang L., Wu T., Pan Y., Liu G.: Synthesis of low-electrical-conductivity graphene/pernigraniline composites and their application in corrosion protection. Carbon, 79, 605-614 (2014).

https://doi.org/10.1016/j.carbon.2014.08.021

[21] Yang Z., Wang L., Sun W., Li S., Zhu T., Liu W., Liu G.: Superhydrophobic epoxy coating modified by fluorographene used for anti-corrosion and self-cleaning. Applied Surface Science, 401, 146-155 (2017). https://doi.org/10.1016/j.apsusc.2017.01.009

[22] Zhan Y., Zhang J., Wan X., Long Z., He S., He Y.: Epoxy composites coating with $\mathrm{Fe}_{3} \mathrm{O}_{4}$ decorated graphene oxide: Modified bio-inspired surface chemistry, synergistic effect and improved anti-corrosion performance. Applied Surface Science, 436, 756-767 (2018). https://doi.org/10.1016/j.apsusc.2017.12.095

[23] Liu Y., Huang J., Tan J., Zeng Y., Liu J., Zhang H., Pei Y., Xiang X., Liu Y.: Intrinsic high-barrier polyimide with low free volume derived from a novel diamine monomer containing rigid planar moiety. Polymer, 114, 289-297 (2017).

https://doi.org/10.1016/j.polymer.2017.03.006

[24] Huang C-C., Jang G-W., Chang K-C., Hung W-I., Yeh J-M.: High-performance polyimide-clay nanocomposite materials based on a dual intercalating agent system. Polymer International 57, 605-611 (2008).

https://doi.org/10.1002/pi.2381

[25] Lei X., Chen Y., Qiao M., Tian L., Zhang Q.: Hyperbranched polysiloxane (HBPSi)-based polyimide films with ultralow dielectric permittivity, desirable mechanical and thermal properties. Journal of Materials Chemistry C, 4, 2134-2146 (2016).

https://doi.org/10.1039/C5TC03391H

[26] Meador M. A. B., Malow E. J., Silva R., Wright S., Quade D., Vivod S. L., Guo H., Guo J., Cakmak M.: Mechanically strong, flexible polyimide aerogels crosslinked with aromatic triamine. ACS Applied Materials and Interfaces, 4, 536-544 (2012).

https://doi.org/10.1021/am2014635

[27] Tsai M-H., Huang S-L., Chiang P-C., Chen C-J.: Morphology, dynamic mechanical properties, and gas separation of crosslinking silica-containing polyimide nanocomposite thin film. Journal of Applied Polymer Science, 106, 3185-3192 (2007).

https://doi.org/10.1002/app.26830

[28] Huang T-C., Yeh T-C., Huang H-Y., Ji W-F., Chou Y-C., Hung W-I., Yeh J-M., Tsai M-H.: Electrochemical studies on aniline-pentamer-based electroactive polyimide coating: Corrosion protection and electrochromic properties. Electrochimica Acta, 56, 10151-10158 (2011). https://doi.org/10.1016/j.electacta.2011.08.114
[29] Huang T-C., Yeh L-C., Lai G-H., Huang B-S., Yang T-I., Hsu S-C., Lo A-Y., Yeh J-M.: Advanced superhydrophobic electroactive fluorinated polyimide and its application in anticorrosion coating. International Journal of Green Energy, 14, 113-120 (2017). https://doi.org/10.1080/15435075.2016.1233495

[30] Marcano D. C., Kosynkin D. V., Berlin J. M., Sinitskii A., Sun Z., Slesarev A., Alemany L. B., Lu W., Tour J. M.: Improved synthesis of graphene oxide. ACS Nano, 4, 4806-4814 (2010). https://doi.org/10.1021/nn1006368

[31] Kim J., Im H., Kim J-M., Kim J.: Thermal and electrical conductivity of $\mathrm{Al}(\mathrm{OH})_{3}$ covered graphene oxide nanosheet/epoxy composites. Journal of Materials Science, 47, 1418-1426 (2012). https://doi.org/10.1007/s10853-011-5922-9

[32] Yin M., Li F., Yan Y., Liu X., Wang C., Chao D.: Poly(aryl ether) bearing electroactive tetraaniline pendants and allyl groups: Synthesis, photo-crosslinking and electrochemical properties. Journal of Polymer Science Part A: Polymer Chemistry, 54, 2321-2330 (2016). https://doi.org/10.1002/pola.28103

[33] Li S., Zhao C., Wang Y., Li H., Li Y.: Synthesis and electrochemical properties of electroactive anilinedimer-based benzoxazines for advanced corrosion-resistant coatings. Journal of Materials Science, 53, 7344-7356 (2018). https://doi.org/10.1007/s10853-018-2113-y

[34] Qu G., Li F., Berda E. B., Chi M., Liu X., Wang C., Chao D.: Electroactive polyurea bearing oligoaniline pendants: Electrochromic and anticorrosive properties. Polymer, 58, 60-66 (2015).

https://doi.org/10.1016/j.polymer.2014.12.033

[35] Huang T-C., Yeh T-C., Huang H-Y., Ji W-F., Lin T-C., Chen C-A., Yang T-I., Yeh J-M.: Electrochemical investigations of the anticorrosive and electrochromic properties of electroactive polyamide. Electrochimica Acta, 63, 185-191 (2012).

https://doi.org/10.1016/j.electacta.2011.12.087

[36] Ramadas M., Bharath G., Ponpandian N., Ballamurugan A. M.: Investigation on biophysical properties of hydroxyapatite/graphene oxide (HAp/GO) based binary nanocomposite for biomedical applications. Materials Chemistry and Physics, 199, 179-184 (2017). https://doi.org/10.1016/j.matchemphys.2017.07.001

[37] Qin L., Zhao Y., Liu J., Hou J., Zhang Y., Wang J., Zhu J., Zhang B., Lvov Y., van der Bruggen B.: Oriented clay nanotube membrane assembled on microporous polymeric substrates. ACS Applied Materials and Interfaces, 8, 34914-34923 (2016). https://doi.org/10.1021/acsami.6b12858

[38] Mehboob S., Mehmood M., Ahmed M., Ahmad J., Tanvir M. T., Ahmad I., ul Hassan S. M.: Terahertz time domain spectroscopy of amorphous and crystalline aluminum oxide nanostructures synthesized by thermal decomposition of AACH. Materials Chemistry and Physics, 191, 62-69 (2017).

https://doi.org/10.1016/j.matchemphys.2017.01.030 
[39] Hernadi K., Couteau E., Seo J. W., Forró L.: Al(OH))/ multiwalled carbon nanotube composite: Homogeneous coverage of $\mathrm{Al}(\mathrm{OH})_{3}$ on carbon nanotube surfaces. Langmuir, 19, 7026-7029 (2003).

https://doi.org/10.1021/la034432

[40] Pourhashem S., Vaezi M. R., Rashidi A., Bagherzadeh M. R.: Distinctive roles of silane coupling agents on the corrosion inhibition performance of graphene oxide in epoxy coatings. Progress in Organic Coatings, 111, 4756 (2017).

https://doi.org/10.1016/j.porgcoat.2017.05.008

[41] Gou J., Wang Y., Li X., Zhou F.: Effect of rare earth oxide nano-additives on the corrosion behavior of $\mathrm{Fe}$ based hardfacing alloys in acid, near-neutral and alkaline $3.5 \mathrm{wt} \% \mathrm{NaCl}$ solutions. Applied Surface Science, 431, 143-151 (2018).

https://doi.org/10.1016/j.apsusc.2017.06.203

[42] Huang H-Y., Huang T-C., Lin J-C., Chang J-H., Lee Y-T., Yeh J-M.: Advanced environmentally friendly coatings prepared from amine-capped aniline trimerbased waterborne electroactive polyurethane. Materials Chemistry and Physics, 137, 772-780 (2013).

https://doi.org/10.1016/j.matchemphys.2012.09.063

[43] Huang T-C., Lai G-H., Li C-E., Tsai M-H., Wan P-Y., Chung Y-H., Lin M-H.: Advanced anti-corrosion coatings prepared from $\alpha$-zirconium phosphate/polyurethane nanocomposites. RSC Advances, 7, 9908-9913 (2017).

https://doi.org/10.1039/C6RA27588E

[44] Huang T-C., Hsieh C-F., Yeh T-C., Lai C-L., Tsai M-H., Yeh J-M.: Comparative studies on corrosion protection properties of polyimide-silica and polyimide-clay composite materials. Journal of Applied Polymer Science, 119, 548-557 (2011).

https://doi.org/10.1002/app.32669

[45] Park S-H., Lee H. S., Choi J. H., Jeong C. M., Sung M. H., Park H. J.: Improvements in barrier properties of poly(lactic acid) films coated with chitosan or chitosan/clay nanocomposite. Journal of Applied Polymer Science, 125, E675-E680 (2012).

https://doi.org/10.1002/app.36405

[46] Ashori A.: Effects of graphene on the behavior of chitosan and starch nanocomposite films. Polymer Engineering and Science, 54, 2258-2263 (2014).

https://doi.org/10.1002/pen.23774

[47] Tan B., Thomas N. L.: A review of the water barrier properties of polymer/clay and polymer/graphene nanocomposites. Journal of Membrane Science, 514, 595 612 (2016).

https://doi.org/10.1016/j.memsci.2016.05.026
[48] Yu Y-H., Lin Y-Y., Lin C-H., Chan C-C., Huang Y-C.: High-performance polystyrene/graphene-based nanocomposites with excellent anti-corrosion properties. Polymer Chemistry, 5, 535-550 (2014).

https://doi.org/10.1039/C3PY00825H

[49] Sheng X., Cai W., Zhong L., Xie D., Zhang X.: Synthesis of functionalized graphene/polyaniline nanocomposites with effective synergistic reinforcement on anticorrosion. Industrial and Engineering Chemistry Research, 55, 8576-8585 (2016).

https://doi.org/10.1021/acs.iecr.6b01975

[50] Gu L., Liu S., Zhao H., Yu H.: Facile preparation of water-dispersible graphene sheets stabilized by carboxylated oligoanilines and their anticorrosion coatings. ACS Applied Materials and Interfaces, 7, 1764117648 (2015). https://doi.org/10.1021/acsami.5b05531

[51] Sun W., Wang L., Wu T., Wang M., Yang Z., Pan Y., Liu G.: Inhibiting the corrosion-promotion activity of graphene. Chemistry of Materials, 27, 2367-2373 (2015). https://doi.org/10.1021/cm5043099

[52] Xiao Y-K., Ji W-F., Chang K-S., Hsu K-T., Yeh J-M., Liu W-R.: Sandwich-structured rGO/PVDF/PU multilayer coatings for anti-corrosion application. RSC Advances, 7, 33829-33836 (2017). https://doi.org/10.1039/C7RA05674E

[53] Yu Z., Di H., Ma Y., Lv L., Pan Y., Zhang C., He Y.: Fabrication of graphene oxide-alumina hybrids to reinforce the anti-corrosion performance of composite epoxy coatings. Applied Surface Science, 351, 986-996 (2015). https://doi.org/10.1016/j.apsusc.2015.06.026

[54] Qiu S., Chen C., Zheng W., Li W., Zhao H., Wang L.: Long-term corrosion protection of mild steel by epoxy coating containing self-doped polyaniline nanofiber. Synthetic Metals, 229, 39-46 (2017). https://doi.org/10.1016/j.synthmet.2017.05.004

[55] Qian R., Yu J., Wu C., Zhai X., Jiang P.: Alumina-coated graphene sheet hybrids for electrically insulating polymer composites with high thermal conductivity. RSC Advances, 3, 17373-17379 (2013).

https://doi.org/10.1039/C3RA42104J

[56] Sun R., Yao H., Zhang H-B., Li Y., Mai Y-W., Yu Z-Z.: Decoration of defect-free graphene nanoplatelets with alumina for thermally conductive and electrically insulating epoxy composites. Composites Science and Technology, 137, 16-23 (2016).

https://doi.org/10.1016/j.compscitech.2016.10.017 